\title{
METHODS
}

\section{A diagnostic decision rule for management of children with meningeal signs}

\author{
Rianne Oostenbrink ${ }^{1,2}$, Carl G.M. Moons ${ }^{2}$, Arda G. Derksen-Lubsen ${ }^{3}$, Diederick \\ E. Grobbee ${ }^{2} \&$ Henriette A. Moll ${ }^{1}$ \\ ${ }^{1}$ Department of General Paediatrics, Sophia Children's Hospital, Erasmus Medical Centre Rotterdam, Rotterdam; ${ }^{2}$ Julius \\ Centre for Health Sciences and Primary Care, University Medical Centre Utrecht, Utrecht; ${ }^{3}$ Juliana Children's Hospital, The \\ Hague, The Netherlands
}

Accepted in revised form 29 July 2003

\begin{abstract}
In a previous study we devised a diagnostic decision rule to improve management of children with meningeal signs, suspected of having bacterial meningitis. The decision rule aimed to guide decisions on (1) whether a lumbar puncture is necessary in children with meningeal signs, and (2) which children need hospitalisation and empirical antibiotic treatment for bacterial meningitis. In this study we assessed the validity of this rule in an external population of four (paediatric) hospitals in The Netherlands. The decision rule included two scoring algorithms using symptoms, signs and quickly available blood and cerebrospinal fluid (CSF) laboratory tests. To evaluate the discriminative value of both algorithms, the absolute numbers of correctly diagnosed patients and the area under the receiver operator characteristic curve were estimated, and compared with the results from the original popula-
\end{abstract}

tion $(\mathrm{n}=360)$. In a 18 month period, we included 226 children, median age 2.2 years, who visited the emergency department with meningeal signs. Bacterial meningitis was present in $25(11 \%)$. Using the scoring algorithms patients could be categorised in groups of increasing risk of bacterial meningitis. The discriminative values of the clinical and CSF algorithm in this new population were similar to those in the original population. In the total population of 586 children with meningeal signs, the rule selected 205 children $(35 \%)$ who did not need a lumbar puncture and 366 children who did not need empirical treatment $(62 \%)$. In conclusion, this diagnostic rule performed well in a new population of children with meningeal signs. This diagnostic decision rule is a valuable tool for the clinician when deciding to treat these children for bacterial meningitis and thus improving their management.

Key words: Bacterial meningitis, Diagnostic decision rule, Sensitivity and specificity

Abbreviations: $\mathrm{BM}=$ bacterial meningitis; $\mathrm{CI}=$ confidence interval; $\mathrm{CSF}=$ cerebrospinal fluid; $\mathrm{ROC}=$ receiver operating characteristic

\section{Introduction}

Children with meningeal signs are highly suspected for bacterial meningitis [1, 2], but these signs may arise from other causes as well $[3,4]$. Many clinical symptoms and signs, and laboratory tests of blood and cerebrospinal fluid (CSF) have been evaluated, but none of them completely discriminate between presence and absence of bacterial meningitis [5-9]. Since delayed diagnosis and treatment of bacterial meningitis worsens its prognosis, physicians have a low threshold to perform a lumbar puncture and to start empirical antibiotic treatment for bacterial meningitis in these children. Hence, lumbar punctures and empirical treatment as performed in these children may, to some extent, be regarded unnecessary afterwards.
In practice, two main questions arise: (1) Based on clinical symptoms and signs, is a lumbar puncture necessary to rule out bacterial meningitis, and (2) based on the direct CSF analysis, is empirical antibiotic treatment necessary until definite cultures become available? With these two questions in mind, we developed in a previous study a diagnostic decision rule to guide decisions on the use of a lumbar puncture and empirical antibiotic treatment for bacterial meningitis in children with meningeal signs, which showed good performance $[10,11]$. The aim of this present study was to prospectively validate the performance of the rule in new patients with meningeal signs at the paediatric emergency department of four hospitals, which is a proper methodological standard before implementing a prediction rule in clinical practice [12-15]. 


\section{Methods \\ Description of the original diagnostic rules}

In an earlier study, we studied 360 children with meningeal signs admitted between 1988 and 1998 to a large paediatric teaching hospital, with an emergency department receiving about 2500 new patients each year, of whom $90 \%$ present for basic paediatric care [16]. Using logistic regression analysis, we identified independent predictors for bacterial meningitis from patients' history, physical examination and laboratory tests. Based on these variables we developed a diagnostic decision rule for children suspected of having bacterial meningitis. The rule includes two scoring algorithms (see Appendix 1 and previous publications $[10,11]$ for details). With the first algorithm a clinical score (ranging from 0.5 to 30 ) can be computed for each patient using six clinical characteristics. The second algorithm yields a CSF score (ranging from -5 to 5 ) by assigning the patient points for two CSF indices. As an example, consider a boy with complaints since half a day, who vomits, with meningeal irritation at physical examination, a serum CRP of $45 \mathrm{mg} / 1,150$ polymorphonuclear cells in $\mathrm{CSF} / \mu \mathrm{l}$ and a CSF/blood glucoseratio of 0.45 . He gets a clinical score of $10(=0.5+2+7.5+0+0+0)$ and a CSF score of $0(=2-2)$.

\section{Description of the validation study}

\section{Setting and procedures}

After approval of the medical ethical committees of the participating hospitals, the rule was prospectively validated in two teaching and two regional hospitals in The Netherlands. We informed the clinicians working at the emergency department (paediatricians and paediatricians in training) that independent predictors for bacterial meningitis had been identified and included in a decision rule. To validate its performance in other patient populations, they were asked to systematically document the presence or absence of the predictors in the rule. Although the clinicians received information how to calculate the scores, they were instructed that the true decision to perform a lumbar puncture or initiate empirical treatment was still left to their own judgement, since the aim of the study was not to implement but only to validate the rule in a new patient population.

\section{Patients}

Children, aged from 1 month up to 15 years, who visited the emergency department with meningeal signs, without pre-existent neurological diseases were eligible for this study. The label 'meningeal signs' was applied (as in the derivation study) to (1) children with a history of pain in the neck, (2) those referred by the general practitioner for meningeal signs, or (3) children with meningeal irritation as assessed by the paediatrician $[10,11,17]$. To ensure enrolment of all patients with 'meningeal signs' we carefully checked the emergency department log during the study period. Patients were included in the period of November 1999-May 2001.

\section{Data collection}

All items of the two algorithms and some additional general characteristics, symptoms, signs, and laboratory tests were systematically documented for each included child. The outcome was the presence of bacterial meningitis, defined as the presence of elevated leukocyte count $(>5$ cells $/ \mu \mathrm{l})$ in CSF of a non-traumatic puncture and a positive bacterial CSF or blood culture [2]. Elevated CSF leukocyte count with viral growth in CSF or faeces or positive viral serology was considered as a case of viral meningitis and absence of any isolated pathogen as a case of aseptic meningitis [18]. Final diagnoses other than meningitis were determined by either bacteriologic cultures of blood, urine, stool and ear, nose, or throat specimens or based on a consensus diagnosis, including a 1-week outpatient follow-up [17]. To the latter aim, data on recovery of non-hospitalised patients were collected at their control visit or by telephone call within 3-7 days after first admission by one of the paediatricians (in training) or the research fellow.

\section{Analysis}

The original rules (as obtained from the derivation study) were applied to the data of the validation set. We estimated the distribution of patients across categories of the score enabling quantification of the predictive values per scoring category, and compared these figures with the findings in the derivation set. We also quantified the overall (i.e. irrespective of score thresholds) diagnostic value of the rules using the area under the receiver operator characteristic curve (ROC area) with $95 \%$ confidence interval (CI) and compared it with the derivation study results [19].

\section{Results}

\section{Patient characteristics}

The validation population comprised 226 patients. A lumbar puncture had been performed in $146(65 \%)$ children (Figure 1). One-hundred and seven children with early discharge (with or without lumbar puncture, 46 and 61, respectively) recovered uneventfully as documented during the outpatient department visit or telephone call. Follow-up on eleven children was lacking, since they did not come to their control visit, and could not be reached by phone. Patient characteristics are presented in Table 1 and compared with those of the derivation set. Patients in the validation 


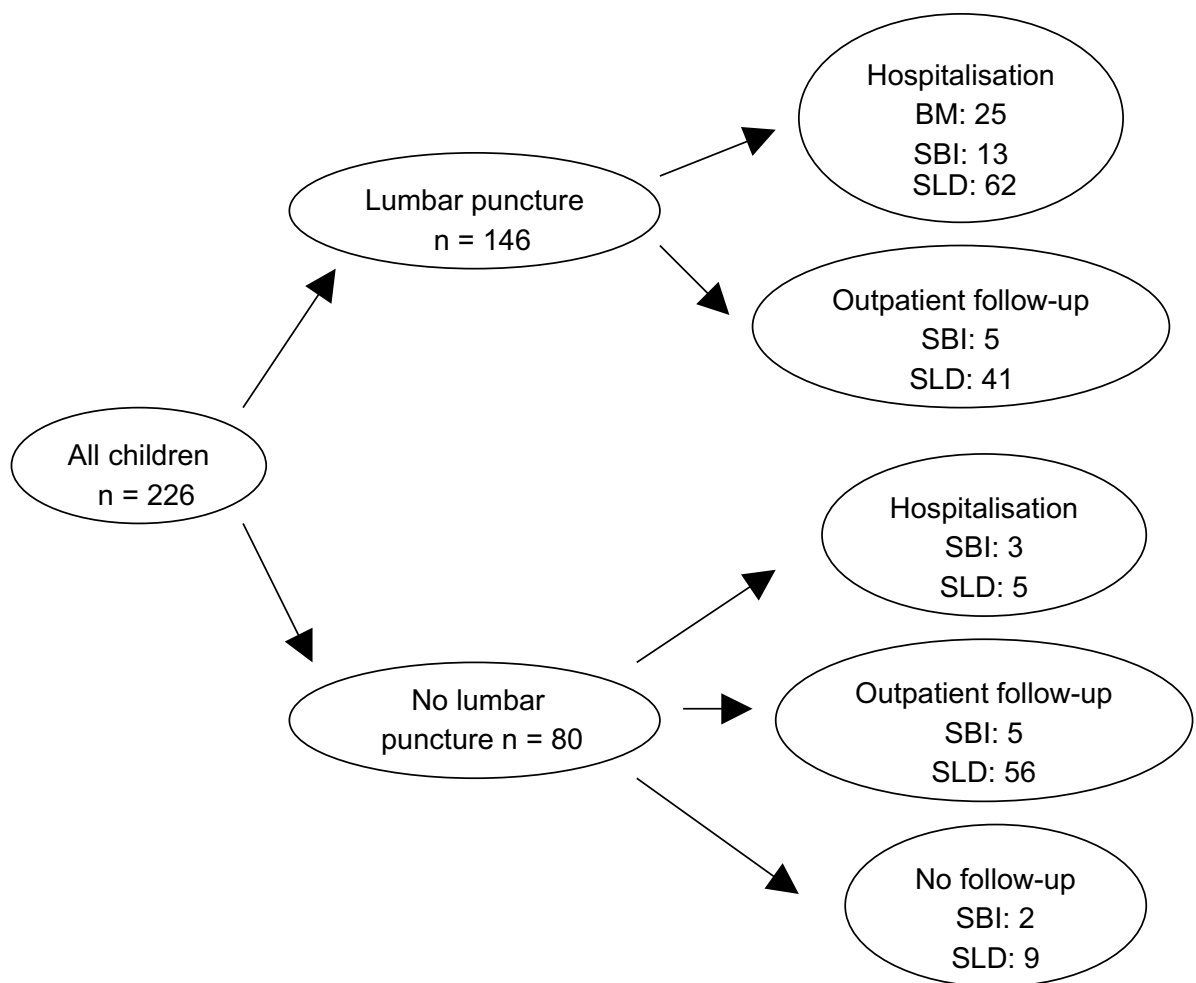

Figure 1. Flow chart of applied management to the 226 children with meningeal signs BM: Bacterial meningitis; SBI: Serious bacterial infections (other than BM); SLD: Self-limiting diseases.

set presented less frequently with a disturbed consciousness and were less frequently hospitalised than those in the derivation set. Although children were rather equally referred with meningeal signs by the general practitioner $(60 \%)$, the paediatrician less frequently confirmed presence of meningeal irritation in the validation set $(64$ of $139 ; 46 \%)$ than in the derivation set (133 of $203 ; 66 \%$ ). The frequency of bacterial meningitis in the validation set was substantially lower than in the original population (11 and $28 \%$, respectively).

\section{Validation of the clinical scoring rule}

In the derivation study we had defined a clinical score of 9.5 to discriminate between children with and

Table 1. General characteristics of derivation and validation set

\begin{tabular}{|c|c|c|}
\hline Characteristic & Derivation set $\mathrm{N}=360$ & Validation set $\mathrm{N}=226$ \\
\hline Male gender & $225(63 \%)$ & $152(67 \%)$ \\
\hline Age $(\text { years })^{\mathrm{a}}$ & $2.4(0.8-5.3)$ & $2.2(0.5-6.0)$ \\
\hline Fever in history & $330(92 \%)$ & $212(94 \%)$ \\
\hline Vomiting in history & $182(51 \%)$ & $111(49 \%)$ \\
\hline Duration main problem (days) $^{\mathrm{a}}$ & $1(1-2)$ & $1(1-2)$ \\
\hline Petechiae at examination & $39(11 \%)$ & $26(12 \%)$ \\
\hline Disturbed consciousness & $83(23 \%)$ & $20(9 \%)$ \\
\hline Cyanosis & $10(3 \%)$ & $2(1 \%)$ \\
\hline Serum CRP $(\mathrm{mg} / \mathrm{l})^{\mathrm{a}}$ & $54(14-151)$ & $18(8-70)$ \\
\hline Lumbar puncture & $256(71 \%)$ & $146(65 \%)$ \\
\hline Hospitalisation & $218(61 \%)$ & $108(48 \%)$ \\
\hline \multicolumn{3}{|l|}{ Diagnosis } \\
\hline Bacterial meningitis & $99(28 \%)$ & $25(11 \%)$ \\
\hline Serious other bacterial infection ${ }^{\mathrm{b}}$ & $36(10 \%)$ & $28(12 \%)$ \\
\hline Viral/aseptic meningitis & $44(12 \%)$ & $43(19 \%)$ \\
\hline Other self-limiting disease ${ }^{c}$ & $181(50 \%)$ & $130(58 \%)$ \\
\hline
\end{tabular}

${ }^{\text {a }}$ Median (25th and 75th percentiles).

${ }^{\mathrm{b}}$ Including septicaemia $(\mathrm{n}=2)$, pneumonia $(\mathrm{n}=17)$, urinary tract infection $(\mathrm{n}=9)$.

${ }^{\mathrm{c}}$ Including upper respiratory tract infections $(\mathrm{n}=52)$, viral syndromes $(\mathrm{n}=65)$, other $(\mathrm{n}=13)$. 
Table 2. Validation of the clinical score on derivation and validation set together $(\mathrm{n}=586$ with $21 \% \mathrm{BM})$

\begin{tabular}{llllll}
\hline & \multicolumn{2}{l}{ Clinical score } & & & \\
\cline { 2 - 5 } & $0-8.4$ & $8.5-14.9$ & $15.0-19.9$ & 20.0 \\
\hline Number of patients & 205 & 251 & 60 & 70 \\
Observed prevalence of BM, n $(\% ; 95 \%$ CI $)$ & $0(0 ; 0-2)^{\mathrm{a}}$ & $32(13 ; 9-17)$ & $31(52 ; 39-65)$ & $61(87 ; 79-95)$ \\
\hline
\end{tabular}

Clinical score $=$ duration of complaints $(1$ point per day $)+$ vomiting $($ yes $=2 /$ no $=0)+$ meningeal irritation at examination $($ yes $=7.5 /$ no $=0)+$ disturbed consciousness $($ yes $=8 /$ no $=0)+$ petechiae $($ yes $=4 /$ no $=0)+$ cyanosis $($ yes $=6.5 / \mathrm{no}=0)+\mathrm{CRP}(<50 \mathrm{mg} / 1=0 / 50-99=0.5 / 100-149=1.0 / 150-199=1.5 / \geqslant 200=2.0)$.

$\mathrm{BM}=$ bacterial meningitis; $\mathrm{n}=$ number of patients with $\mathrm{BM}$; $\mathrm{CI}=$ confidence interval.

a $95 \%$ CI was estimated using the exact Clopper-Pearson method.

without bacterial meningitis. Application of this clinical scoring rule to the validation set, however, yielded two children with bacterial meningitis with a clinical score of 8.5 ; all other children with bacterial meningitis $(\mathrm{n}=23)$ had a clinical score of 10.5 or higher. These two would have been missed when applying the original rule at a threshold of 9.5. Of all children without bacterial meningitis $(\mathrm{n}=201), 122$ had a score $<9.5$, yielding 79 with a score of 9.5 or higher. The ROC-area of the clinical score in the validation set was 0.90 (95\% CI: 0.84-0.95), which was slightly lower than in the original data set (ROCarea 0.94 ; 95\% CI: 0.91-0.96) [10].

Given that missing a case of bacterial meningitis was unacceptable, we adjusted the original threshold for the indication of a lumbar puncture from 9.5 to 8.5. To quantify how well this 'new' rule would perform, we tested it on all available data, i.e. on the patients from the derivation and validation study together $(\mathrm{n}=586)$. Of these, $124(21 \%)$ had BM and $462(79 \%)$ had not. The results are given in Table 2. It can be seen that under a score of 8.5 , no patients with $\mathrm{BM}$ would now be missed. Also, the predictive value of bacterial meningitis sharply increased with increasing scores.

\section{Validation of CSF scoring rule}

Table 3 presents the observed frequency of bacterial meningitis according to the CSF score in the valida- tion set. The frequency of bacterial meningitis increased with the CSF score. The frequency of bacterial meningitis in the validation set was comparable to the frequency found in the derivation study, except for the second column (CSF score -3 to -1). The ROC-area of the CSF score in the validation set $(0.97 ; 95 \%$ CI: $0.93-1.0)$ was similar to the ROCarea in the derivation set $(0.93$; $95 \%$ CI: $0.89-0.97)$ [11].

\section{Validation of the two scoring rules combined}

In contrast to the clinical score, we could not define a threshold value for the CSF rule to rule out BM, as was also the case in the derivation study. We therefore evaluated the diagnostic value of the combined use of the 'new' clinical rule and the (original) CSF score using all available data from the derivation and validation study $(\mathrm{n}=586)$, as presented in Figure 2 .

Patients with high clinical scores $(\geqslant 20)$ were at high risk of bacterial meningitis, and the CSF score aided little in distinguishing between patients with and without bacterial meningitis. In these patients however, a lumbar puncture will identify the pathogen. In the intermediate scoregroups (clinical score 8.5-19.9), the use of the CSF score with the clinical score could select a substantial number of patients without bacterial meningitis, such that empirical treatment could be safely omitted. Since bacterial meningitis was not observed in patients with a clinical

Table 3. Validation of the CSF score on validation set

\begin{tabular}{|c|c|c|c|c|}
\hline & \multicolumn{4}{|l|}{ CSF score } \\
\hline & $<-3.0$ & -3.0 to -1.0 & -0.5 to 0.5 & $\geqslant 1.0$ \\
\hline \multicolumn{5}{|l|}{ Validation set } \\
\hline Number of patients ${ }^{\mathrm{a}}$ & 21 & 55 & 27 & 13 \\
\hline Observed prevalence of $\mathrm{BM}, \mathrm{n}(\% ; 95 \% \mathrm{CI})$ & $0(0 ; 0-16)$ & $1(2 ; 0-5)$ & $7(26 ; 8-44)$ & $13(100 ; 75-100)$ \\
\hline \multicolumn{5}{|l|}{ Derivation set } \\
\hline Observed prevalence BM (\%) & $3 \%$ & $10 \%$ & $34 \%$ & $97 \%$ \\
\hline
\end{tabular}



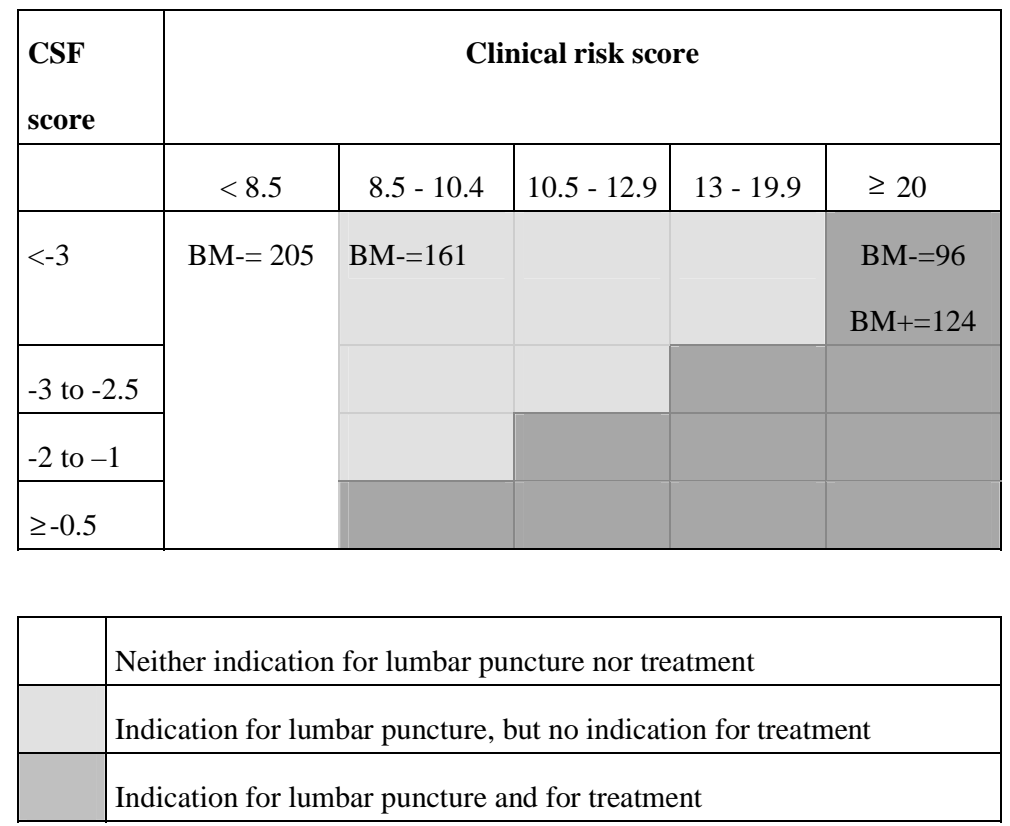

Figure 2. Distribution of patients with $(\mathrm{BM}+)$ and without $(\mathrm{BM}-)$ bacterial meningitis from derivation and validation set across categories of both scores in the decision rule.

score $<8.5$, the CSF score had no additional diagnostic value in these patients.

Using the thresholds as presented in Figure 2, 205 children with a score $<8.5$ could be selected in whom a lumbar puncture was not necessary. Subsequently, 381 children would undergo a lumbar puncture. In current practice 402 children underwent a lumbar puncture (Table 1), of which 21 could have been prevented by the rule $(5 \%)$. In addition, the rule selected 366 children in whom empirical treatment could be withheld (Figure 2, white and grey area). Doing so, the rule could reduce the number of hospitalisations from 326 (Table 1) to 220 (33\% reduction).

\section{Discussion}

The principle aim of diagnostic protocols is improve patient management. Clinical prediction rules may not perform as well in new settings as they had in the settings in which they were developed $[12,14,20]$. Therefore, prospective validation of a rule should inform about whether the rule reflects true associations rather than the play of chance or statistical 'overfitting' and whether they can be applied appropriately in practice. In this present study we have validated a diagnostic decision rule, as previously devised, to guide two questions in children presenting with meningeal signs: when to perform a lumbar puncture, and when to start empirical antibiotic treatment, without missing a single case of bacterial meningitis. In a new group of 226 children visiting the emergency department with meningeal signs, the scoring algorithms of this rule using symptoms and signs at presentation and quickly available blood and CSF laboratory tests appear to be valid. Use of this rule will reduce (unnecessary) lumbar punctures and hospitalisations and their associated costs. The estimated number of prevented lumbar punctures by the rule may seem rather limited, due to the assumption not to miss any child with meningeal signs. The potential savings in number of hospitalisations are much higher. Since there may be other reasons for diagnostic procedures (e.g. prognostication) or hospitalisation (e.g. co-morbidity) the precise reduction of lumbar punctures and hospitalisation should be estimated in an implementation study [21].

In 126 patients (of whom 4 with bacterial meningitis) the CSF score could not be computed since values for either the CSF cell count, or glucose concentration in CSF or serum were missing due to laboratory technical reasons. These patients were excluded from further analysis, which explains part of the difference between the observed number of cases of the validation and derivation set in Table 3 .

The threshold value of 9.5 for lumbar puncture as defined in the derivation set would have missed two children with bacterial meningitis in the validation set. One of those was a 34-days old boy, prematurely born, and thus at the borderline of the age criteria of our rule (patients aged from 1 month up to 15 years). He had a 1-day history of complaints, meningeal irritation at physical examination, and a serum CRP of $2 \mathrm{mg} / 1$. CSF contained 11,310 cells $/ \mu \mathrm{l}(90 \%$ polymorphonuclear cells) and the $\mathrm{CSF} /$ blood glucoseratio was 0.49 . E. coli was isolated from CSF. The other was a 6-month old boy, with complaints since half a 
day and a generalised seizure of 10 min. At examination he developed a second generalised seizure. Serum CRP was $68 \mathrm{mg} / 1$, and $\mathrm{CSF}$ contained 2700 cells/ $\mu 1$ (polymorphonuclear cells only); CSF/ blood glucose ratio was 0.61 . S. pneumoniae was isolated from CSF and blood. Obvious, the combination of seizures and meningeal signs is very indicative of bacterial meningitis. In a population of children with meningeal signs as the main symptom seizures occur too infrequently to be included in a diagnostic prediction rule. It should be noted that the clinical score threshold value for a lumbar puncture was defined under the assumption not to miss any case of bacterial meningitis. Application of the rule may miss some cases of viral meningitis $(n=9$ of 43 ; $20 \%$ in the present validation study). We believe that this is acceptable, since viral meningitis in children aged $>1$ month has a fair prognosis and does not need specific treatment [22]. This point of view, however, may change in future if antiviral therapy for enteroviral meningitis becomes available.

The evaluation of potential diagnostic predictors for bacterial meningitis has resulted in various prediction rules with predictors comparable to ours [5-9, $23,24]$. Only few have been validated as well $[8,9]$. All these studies selected patients on their final diagnosis rather than on their clinical suspicion of bacterial meningitis. Selection of patients on their diagnosis can lead to biased selection of the most evident cases with subsequent potential overestimation of the diagnostic value of tests that are applied in practice on all patients with meningeal signs [25-27]. In accordance with clinical practice, the value of diagnostic tests should be assessed in patients with suspicion on a particular disease. Therefore, we included patients suspected of having bacterial meningitis, i.e. patients visiting the emergency department with meningeal signs. Following this type of patient selection, our diagnostic rule does not apply to all patients suspected of having meningitis, since patients with a prominence of other symptoms of meningitis (such as coma, convulsions, etc. $[1,2]$ ) are not included in our study population.

Some comments on the use of the rule and its generalisability need to be made. Inclusion of serum CRP in our rule suggests that CRP results are necessarily available before drawing conclusions. Due to its positive value in the rule, CRP will always increases the total score. As a consequence, CRP will not change the indication for lumbar puncture in patients with a score above the threshold value for lumbar puncture $(\geqslant 8.5)$ based on clinical variables only (i.e. before knowing serum CRP). These patients are probably the evident cases of bacterial meningitis, in whom further diagnostic tests are quite straightforward. To include serum CRP is valuable in the less evident cases (with clinical score $<8.5$ ), in particular.
In this validation study, the prevalence of bacterial meningitis in children with meningeal signs was substantially lower than in the population the rule was derived on. This may be due to the routine Haemophilus influenzae type B-vaccination of infants, as introduced in the Netherlands since 1996 [28, 29]. Since the value of a prediction rule may be affected by differences in disease prevalence in different populations [26, 30, 31], we estimated the performance of both the clinical and CSF algorithm, after adjusting the intercepts of the two original logistic regression models $[10,11]$, from which the scoring rules in the appendix were derived. This adjustment showed neither an effect on the ROC-areas nor on the predictive accuracy in terms of absolute number of patients. We therefore believe that an adjustment for differences in disease-prevalence is not necessary and that the rule can be used without adaptation in other places with a different prevalence of meningitis.

Although the rule was derived on retrospectively collected data, it performed similar in the prospectively collected validation set. We therefore believe that the rule including the symptoms and signs as we defined is well applicable in practice.

The rule was derived in an academic paediatric hospital (receiving about $90 \%$ basic paediatric care [16] but validated in four hospitals, including three non-academic ones, with their particular patient populations. Since the rule performed well in all hospitals, we state that the rule is applicable to paediatric emergency departments in general.

As the aim of the rule is to detect bacterial meningitis, the rule does not identify the true diagnosis after bacterial meningitis has been ruled out. Further evaluation by the clinician is necessary to reveal other serious bacterial infections, for which treatment is necessary $[3,4]$.

In conclusion, a diagnostic decision rule for children with meningeal signs proved to perform well in a newly selected group of patients. Using this rule, patients can be classified in groups of increasing probability of bacterial meningitis. This diagnostic decision rule can be used as a tool for the clinician to guide decisions on the performance of a lumbar puncture or initiating empirical treatment in children with meningeal signs in order to improve their management.

\section{Acknowledgement}

We thankfully acknowledge R. Spritzer, MD PhD, and P.T.M. van Echtelt, MD, Sint Fransiscus Hospital and L.C. ten Have, MD, Reinier de Graaf Hospital for their participation in this study. This project has been financed by the Health Care Insurance Council of The Netherlands. 


\section{Appendix 1}

Contents of the diagnostic decision rule.

(a) Clinical scoring algorithm.

\begin{tabular}{|c|c|c|c|}
\hline \multirow{2}{*}{$\begin{array}{l}\text { Characteristic } \\
\text { Duration main problem in history }\end{array}$} & \multirow{2}{*}{$\begin{array}{l}\text { Points assigned if characteristic present }{ }^{\mathrm{a}} \\
1 \text { per day }(\max 10)\end{array}$} & \multicolumn{2}{|c|}{$\beta(95 \% \mathrm{CI})^{\mathrm{b}}$} \\
\hline & & 0.4 & $(0.2-0.7)$ \\
\hline \multicolumn{4}{|l|}{ Vomiting in history } \\
\hline Yes & 2 & \multirow[t]{2}{*}{0.8} & \multirow[t]{2}{*}{$(-0.2-1.7)$} \\
\hline No & 0 & & \\
\hline \multicolumn{4}{|c|}{ Meningeal irritation at physical examination } \\
\hline Yes & 7.5 & \multirow[t]{2}{*}{3.1} & \multirow[t]{2}{*}{$(1.0-5.2)$} \\
\hline No & 0 & & \\
\hline \multicolumn{4}{|l|}{ Cyanosis at physical examination } \\
\hline Yes & 6.5 & \multirow[t]{2}{*}{2.6} & \multirow[t]{2}{*}{$(0.1-5.0)$} \\
\hline No & 0 & & \\
\hline \multicolumn{4}{|l|}{ Petechiae at physical examination } \\
\hline Yes & 4 & \multirow[t]{2}{*}{1.6} & \multirow[t]{2}{*}{$(0.3-2.9)$} \\
\hline No & 0 & & \\
\hline \multicolumn{4}{|c|}{ Disturbed consciousness at physical examination } \\
\hline Yes & 8 & \multirow[t]{2}{*}{3.1} & $(2.2-4.0)$ \\
\hline No & 0 & & \\
\hline \multicolumn{4}{|l|}{ Serum CRP (mg/l) } \\
\hline$<50$ & 0 & \multirow{5}{*}{\multicolumn{2}{|c|}{$0.007(0.003-0.011)^{\mathrm{c}}$}} \\
\hline $50-99$ & 0.5 & & \\
\hline $100-149$ & 1.0 & & \\
\hline $150-199$ & 1.5 & & \\
\hline$\geqslant 200$ & 2.0 & & \\
\hline
\end{tabular}

$\beta=$ regression coefficient of the logistic model; $95 \% \mathrm{CI}=95 \%$ confidence interval.

a The score of each predictor was obtained by multiplying the corresponding regression coefficient with 2.5 and rounded to

(b) Cerebrospinal fluid (CSF) scoring algorithm.

\begin{tabular}{lll}
\hline Characteristic & Points assigned if characteristic present ${ }^{\mathrm{a}}$ & $\beta(95 \% \mathrm{CI})^{\mathrm{b}}$ \\
\hline CSF polymorphonuclear cell count $($ per $\mu \mathrm{l})$ & & $1.1(0.8-1.4)^{\mathrm{c}}$ \\
$<10$ & 0 & 2 \\
$10-99$ & 3 & $-4.5(-6.6 \text { to }-2.4)^{\mathrm{d}}$ \\
$100-999$ & 4 & \\
$1000-9999$ & 0 & \\
$\geqslant 10,000$ & -0.5 & \\
CSF/blood glucose ratio & -1.0 & \\
$<0.1$ & -1.5 & \\
$0.1-0.19$ & -2.0 & \\
$0.2-0.29$ & -2.5 & \\
$0.3-0.39$ & -3.0 & \\
$0.4-0.49$ & -3.5 & \\
$0.5-0.59$ & -4.0 & \\
$0.6-0.69$ & -4.5 & \\
$0.7-0.79$ & -5.0 & \\
$0.8-0.89$ & & \\
$0.9-0.99$ & & \\
Total CSF score (sum of scores) & & \\
\hline
\end{tabular}

$\beta=$ regression coefficient of the logistic model; $95 \% \mathrm{CI}=95 \%$ confidence interval.

a The score of each predictor was obtained rounding the corresponding regression coefficient to the nearest integer.

b The intercept (constant) was 0.07 (95\% CI: $-1.3-1.2)$.

${ }^{\mathrm{c}}$ Per unit ${ }^{10} \log$ (CSF polymorphonuclear cell count).

${ }^{\mathrm{d}}$ Per unit glucose CSF/blood ratio. 


\section{References}

1. Valmari P, Peltola H, Ruuskanen O, Korvenranta H. Childhood bacterial meningitis: Initial symptoms and signs related to age, and reasons for consulting a physician. Eur J Pediatr 1987; 146: 515-518.

2. Feigin RD, McCracken Jr., GH, Klein JO. Diagnosis and management of meningitis. Pediatr Infect Dis $\mathbf{J}$ 1992; 11: 785-814.

3. Levy M, Wong E, Fried D. Diseases that mimic meningitis. Analysis of 650 lumbar punctures. Clin Pediatr 1990; 29: 254-255, 258-261.

4. Barnett ED, Bauchner H, Teele DW, Klein JO. Serious bacterial infections in febrile infants and children selected for lumbar puncture. Pediatr Infect Dis J 1994; 13: 950-953.

5. Carraccio C, Blotny K, Fisher MC. Cerebrospinal fluid analysis in systemically ill children without central nervous system disease. Pediatrics 1995; 96: 48-51.

6. Freedman SB, Marrocco A, Pirie J, Dick PT. Predictors of bacterial meningitis in the era after Haemophilus influenzae. Arch Pediatr Adolesc Med 2001; 155: 13011306.

7. Hoen B, Viel JF, Paquot C, Gerard A, Canton P. Multivariate approach to differential diagnosis of acute meningitis. Eur J Clin Microbiol Infect Dis 1995; 14: 267-274.

8. Nigrovic LE, Kuppermann N, Malley R. Development and validation of a multivariable predictive model to distinguish bacterial from aseptic meningitis in children in the post-Haemophilus influenzae era. Pediatrics 2002; 110: 712-719.

9. Negrini B, Kelleher KJ, Wald ER. Cerebrospinal fluid findings in aseptic versus bacterial meningitis. Pediatrics 2000; 105: 316-319.

10. Oostenbrink R, Moons KGM, Donders ART, Grobbee DE, Moll HA. Prediction of bacterial meningitis in children with meningeal signs: Reduction of lumbar punctures. Acta Paediatr 2001; 90: 611-617.

11. Oostenbrink R, Moons KGM, Twijnstra MJ, Grobbee DE, Moll HA. Children with meningeal signs: Predicting who needs empirical antibiotic treatment. Arch Ped Adol Med 2002; 156: 1189-1194.

12. Harrell FE, Jr., Lee KL, Mark DB. Multivariable prognostic models: Issues in developing models, evaluating assumptions and adequacy, and measuring and reducing errors. Stat Med 1996; 15: 361-387.

13. Laupacis A, Sekar N, Stiell IG. Clinical prediction rules. A review and suggested modifications of methodological standards. JAMA 1997; 277: 488-494.

14. McGinn TG, Guyatt GH, Wyer PC, Naylor CD, Stiell IG, Richardson WS. Users' guides to the medical literature. XXII: How to use articles about clinical decision rules. JAMA 2000; 284: 79-84.

15. Justice AC, Covinsky KE, Berlin JA. Assessing the generalizability of prognostic information. Ann Intern Med 1999; 130: 515-524.

16. van Steensel-Moll HA, Jongkind CJ, Aarsen RSR, et al. A problem oriented patient classification system for general pediatrics II. [in Dutch, English summary]. Tijdschr Kindergeneesk 1996; 64: 99-104.

17. Oostenbrink R, Theunissen CCW, Moons KGM, Derksen-Lubsen G, Grobbee DE, Moll HA. Signs of meningeal irritation at the emergency department; how often bacterial meningitis? Pediatr Emerg Care 2001; 17: 161-164.

18. Maxson S, Jacobs RF. Viral meningitis. Tips to rapidly diagnose treatable causes. Postgrad Med 1993; 93: 153156, 159-160, 163-166.

19. Hanley JA, McNeil BJ. The meaning and use of the area under a receiver operating characteristic (ROC) curve. Radiology 1982; 143: 29-36.

20. Randolph AG, Guyatt GH, Calvin JE, Doig G, Richardson WS. Understanding articles describing clinical prediction tools. Crit Care Med 1998; 26: 16031612.

21. Oostenbrink R, Oostenbrink JB, Moons KGM, et al. Cost reduction by introduction of a diagnostic decision rule in children with meningeal signs. Int $\mathbf{J}$ Technol Assess Health Care, in press.

22. Rotbart HA. Enteroviral infections of the central nervous system. Clin Infect Dis 1995; 20: 971-981.

23. Spanos A, Harrell Jr., FE, Durack DT. Differential diagnosis of acute meningitis. An analysis of the predictive value of initial observations. JAMA 1989; 262: 2700-2707.

24. Deivanayagam N, Ashok TP, Nedunchelian K, Ahamed SS, Mala N. Evaluation of CSF variables as a diagnostic test for bacterial meningitis. J Trop Pediatr 1993; 39: 284-287.

25. van der Schouw YT, van Dijk R, Verbeek ALM. Problems in selecting the adequate patient population from existing data files for assessment studies of new diagnostic tests. J Clin Epidemiol 1995; 48: 417 422.

26. Moons KGM, van Es GA, Michel BW, Büller HR, Habbema JDF, Grobbee DE. Reduncancy of single diagnostic test evaluation. Epidemiology 1999; 10: 276281.

27. Knottnerus JA, Leffers JP. The influence of referral patterns on the characteristics of diagnostic tests. J Clin Epidemiol 1992; 45: 1143-1154.

28. Adams WG, Deaver KA, Cochi SL, et al. Decline of childhood Haemophilus influenzae type b (Hib) disease in the Hib vaccine era. JAMA 1993; 269: 221-226.

29. Conyn-van Spaendonck MA, Veldhuijzen IK, Suijkerbuijk AW, Hirasing RA. Significant decline of the number of invasive Haemophilus influenzae infections in the first 4 years after introduction of vaccination against $H$. influenzae type B in children [in Dutch, English summary]. Ned Tijdschr Geneeskd 2000; 144: 1069-1073.

30. Poses RM, Cebul RD, Collins IM, Fager SS. The importance of disease prevalence in transporting clinical prediction rules. Ann Int Med 1986; 105: 586-591.

31. Wigton RS, Connor JL, Centor RM. Transportability of a decision rule for the diagnosis of Streptococcal pharyngitis. Arch Intern Med 1986; 146: 81-83.

Address for correspondence: R. Oostenbrink, Sophia Children's Hospital, Erasmus MC Rotterdam, Room Sh 2015, Dr Molewaterplein 60, 3015 GJ Rotterdam, The Netherlands

Phone: + 31-10-4636363; Fax: + 31-10-4636800

E-mail: r.oostenbrink@erasmusmc.nl 